\title{
TRES RETRATOS DE LA MUERTE EN LAS COPLAS DE JORGE MANRIQUE
}

"Para justipreciar la poesía de Jorge Manrique, hay que colocarla en el centro de la gran tradición espiritual de la Edad Media. No quiero referirme a las famosas influencias, a los igualmente famosos precursores, ni mucho menos a las fuentes, adormideras de tantas labores críticas bien intencionadas, y que durante muchos años han suplantado el objetivo verdadero del estudio de la literatura. Todos éstos son factores parciales, agentes menores de una realidad mucho más profunda, de mayor complejidad biológica: la tradición"'1. Estas palabras, escritas hace unos doce años, han tenido ya notable repercusión sobre el estudio de la literatura en lengua española. Si las cito aquí es no sólo por el significado que tienen, sino también, y en igual medida, por el sonido que llevan. ¿Por qué se han puesto en cursiva esas tres palabras, influencias, precursores, fuentes? No se trata de citas; tampoco parece que el autor haya querido atribuirles especial importancia. A quienes recuerdan la voz de Salinas, esas cursivas permiten volver a escuchar el tono de irónica resignación con que tales palabras eran - y siguen siendo- pronunciadas. Porque es ésta una crítica oral, crítica que se dirige a nosotros en persona, por así decir, desde un facistol y desde una garganta. El hombre se ha ido; sólo quedan esas palabras en cursiva. Pero es digno y justo que un poema que termina con la voz viva de un hombre muerto a quien se ha amado, encuentre su más aguda explicación a través de la voz de otro hombre muerto, también amado. Hay aquí —sin que se la haya buscado- una grave armonía entre el poema y la crítica. El presente estudio quiere ser comentario y continuación de esa armonía; quiere dar a entender que el hecho de estudiar las Coplas de Jorge Manrique constituye un acto de homenaje a Pedro Salinas.

Las palabras citadas, a la vez que nos recuerdan tan vívidamente a su autor, nos muestran el camino hacia el poema. Así, por ejemplo, la doctrina de las "tres vidas" es un lugar común de la crítica manriqueana. Pero ¿cómo comprender la forma en que tal doctrina se ha hecho poesía, en que ciertas ideas heredadas han adquirido

${ }^{1}$ Pedro Salinas, Jorge Manrique, o Tradición y originalidad, Buenos Aires, 1947, P. 114 . 
existencia poética? La vida terrenal, la vida de la fama y la vida eterna existen en las Coplas como ideas lo mismo que como representaciones. ¿De qué manera comentarlas bajo ambos aspectos? Las páginas de Salinas constituyen una respuesta no sólo conmovedora, sino también escrupulosamente documentada. El concepto de tradición le ha dado libertad para pasar de Petrarca a Boecio y luego a Pérez de Guzmán, y para percibir la historia literaria, no como proceso que se engendre y se explique a sí mismo, sino como el rastro o la huella que van dejando los poetas. Al superar las nociones de causa y efecto, inadecuadas para el fenómeno creador, Salinas ha evitado la indigna sumisión a la historia en que cayó, por ejemplo, Wölfflin. "El proceso de composición consta de un conjunto de reproducciones de estos o aquellos elementos suministrados por la tradición; sin embargo, la operación total que abarca todas esas operaciones es de carácter creador, y su producto original" (p. 137). En el curso de tal operación es justamente cuando la doctrina de las tres vidas deja de ser lugar común para convertirse en poesía.

Donde más visiblemente se manifiesta esa metamorfosis es en el campo de la estructura. Ahí encontramos a la vista las tres vidas, no sólo explicadas, sino poéticamente desplegadas ante nosotros para que las admiremos. Las Coplas, según podrá ver cada lector, se dividen en tres partes ${ }^{2}$, cada una de ellas dedicada fundamentalmente a una de esas vidas. En primer lugar, un llamado al hombre para que recuerde su condición mortal y su destino divino: a cambio de la muerte genérica, una vida eterna. Después, el impresionante retrato de la vida sensorial, la residencia en la tierra con sus grandiosas figuras humanas, su fascinador engaño, su pirotécnica belleza, tanto más deslumbrante cuanto que es tan transitoria. Y finalmente la vida de la fama, encarnada en don Rodrigo Manrique, una vida "pintada" con su brazo-espada en escenas que muestran sus hazañas y su hombría. De ahí su salvación final. Como brillantemente ha mostrado Américo Castro ${ }^{3}$, las Coplas son ante todo, en sus tres partes, un poema de la vida, un cántico a la vida; en cierto sentido, un triunfo tripartito de la vida, que supera a la tradición ascética de la cual ha brotado. El lector llega a sentir la maravilla que significa cada tipo de vida --la eterna, la terrenal, la de la fama- según se le va mostrando en la parte respectiva del poema. Sin embargo, para

2 El examen estructural e ideológico de las Coplas por Rosemarie Burkhart, "Leben, Tod und Jenseits bei Manrique und Villon" (Kölner Romanistische Arbeiten, t. 1) es, que yo sepa, el primer examen serio de la división tripartita.

"Américo Castro, "Muerte y belleza. Un recuerdo a Jorge Manrique", Nac, 16 de enero de 1930 , estudio recogido ahora en sus Semblanzas y estudios españoles, Princeton, $195^{6}$, pp. $45^{-51}$. La idea central es que Manrique salva y exalta la vida en sus tres formas: "la nota postrera y decisiva es, sin embargo, esa buena confianza en la eficacia de toda enérgica vitalidad, la cual queda resonando gratamente en nuestro ánimo" (p. $5^{1}$ ). 
el poeta y para su padre, el triunfo definitivo - la salvación personal- no es fácil. Sólo aceptando a sabiendas la muerte, sólo por medio de una consciencia adquirida dolorosamente y expresada a través de la poesía, puede lograrse ese triunfo. "Recuerde el alma dormida" es la nota clave, y "Consiento en mi morir / con voluntad plazentera, / clara y pura" es la culminación. Entre ambas coloca Manrique poéticamente, en forma triple, las fuerzas de la vida.

Esta estructura de tres partes es, por sí misma, hondamente tradicional. El más remoto antecedente de las Danzas de la Muerte es un diálogo en verso entre tres vivos y tres muertos. La versión original, el Dit des trois morts et des trois vifs (quizá del siglo xn), sufrió gran número de refundiciones, cambios, ilustraciones y traducciones $^{4}$. Fue, pues, un vehículo poético clásico para la meditación, y, según se ha demostrado ${ }^{5}$, creó la tradición de representar a la muerte en forma tripartita. En ciertas versiones y variaciones emblemáticas se incorporó a las tres Parcas (y aun a las tres Gracias y a los tres Reyes) dentro del macabro encuentro triple. Así, la objeción de que un poema habla de tres vivos mientras que el otro presenta tres vidas no viene al caso. No nos interesa ahora el "designio", la intención explícita, sino lo que Salinas llama el "diseño", la estructura poética. Gráfica, poética, innatamente —esto es, tradicionalmente-, la muerte y los diálogos con la muerte aparecen en forma tripartita. $\mathrm{Y}$ Jorge Manrique tendía a crear desde dentro de la tradición.

En todo caso, el Dit des trois morts nos recuerda el hecho de que en las Coplas cada una de las tres vidas tiene su encuentro con la muerte. Hay tres vidas que encuentran a otras tantas muertes, - pues en este poema la vida no se concibe aparte de la muerte. No debemos, pues, considerar las Coplas como una exposición doctrinal de tres ideas tradicionales sobre la vida, ni tampoco como una nueva exaltación renacentista de la vitalidad. Se trata más bien de tres confrontaciones poéticas de la vida con la muerte, cada una distinta, dependiendo cada una de las otras dos para adquirir pleno sentido. Pero Manrique, a la vez que acepta este esquema heredado, lo altera. En el Dit y en las Danzas es la Muerte, la Muerte personificada, quien da la clave y ocupa el centro de la escena. Aquí, es la vida. Jorge

"Cf. Stefan Glixelli, Les cinq poèmes "Des trois morts et des trois vifs", Paris, 1914. ÉMILE MÂLE, L'art religieux de la fin du moyen âge en France, $\mathrm{Pa}$ ris, 1925, estudia la abundantísima tradición gráica a que dieron lugar esos poemas. J. Huizinga, El otoño de la Edad Media, trad. J. Gaos, Madrid, 199o, considera el Dit como antecedente de las Danzas. Estos tres autores afirman la prioridad y popularidad del Dit des trois morts, lo mismo en la poesía que en las artes plásticas. El hecho de que no se conozca ninguna versión española no afecta fundamentalmente a mi tesis. Glixelli registra versiones alemanas, italianas y latinas. Puede verse más detallada bibliografía en el exhaustivo libro de Hellmut Rosenfeld, Der mittelalterliche Totentanz, Münster-Köln, 1954 .

${ }^{5}$ Véase F. Parkes Weber, Aspects of death, London, 1918, pp. 89-9o. 
Manrique, insatisfecho con la alegoría y con la abstracción figurada, es ante todo un poeta de las cosas que conoce - la vida cortesana, los hechos de su padre-, y como la muerte es incognoscible, deja de ser protagonista. "Death as a counterpoint to life is a way of celebrating life by contrast"'. La muerte se amolda a cada una de las tres vidas de tal manera que hace resaltar su valor específico, su nivel y su intensidad peculiares. En resumen, las Coplas aprovechan a la muerte - se sirven de ella - como medio para convertir en poesía la doctrina tradicional de las tres vidas. Pero no son una elegía ni una meditación sobre la muerte. En su estructura de significación, en su "diseño", la vida asume decididamente la dirección y, en tres vueltas sucesivas, impone su voluntad expresiva a su mortal compañera de baile. Las Coplas son una Danza de la vida. Y la clave de la originalidad de Jorge Manrique es justamente ese enaltecimiento gravemente exquisito de la vida en medio de la tradición cuatrocentista de la muerte.

La primera muerte que aparece en las Coplas es una interrupción o detención de la vida, un alto que se marca al movimiento vital. La tradicional alegoría del mar al cual irán a dar los ríos de nuestras vidas $^{7}$ fija el ritmo y la atmósfera iniciales. Aquí se nos habla de aquella muerte genérica, de aquel "morir" impersonal que, según Salinas, distingue a las Coplas de las Danzas. El poeta describe un proceso natural inexorable al cual está sujeta la vida y que es inseparable de la temporalidad de la vida. Nos hace una advertencia, sin atemorizarnos: no necesitamos sentir miedo, porque en las siguientes estrofas nos recuerda que también existe una vida genérica ("morada sin pesar"), ofrecida por "aquel fijo de Dios". Esta manera curiosamente indirecta de aludir a Cristo parece expresar la impersonalidad de la salvación, el carácter colectivo de la peregrinación ("Este mundo es el camino / para el otro") que todos los cristianos deben emprender. Una muerte genérica, una vida eterna para todos los seguidores de Cristo: tales son los guías de la gran procesión que va a pasar ante nuestros ojos.

Al final del poema, la confrontación de la vida con la muerte es muy otra. Se nos muestra, no la vida en general, sino la vida de don Rodrigo Manrique, una "vida de la fama", a la vez personal y ejemplar. Y la muerte, aunque sigue siendo alegórica, es ahora humana y viva, no inorgánica. No expresada ya por medio de una compa-

- Kenneth Burke, "Thanatopsis for critics", Essays in criticism, 1952, p. 370.

- Anna Krause, Jorge Manrique and the cult of death, Berkeley, Cal., 1937, parece convenir con A. Contrna (Jorge Manrique, Cancionero, Madrid, 1929) en que esta imagen procede del Eclesiastés, 1:7. Pero, como ella misma muestra, la comparación heraclitiana de la fugacidad de la vida con el correr del agua se encuentra también en otros poemas del siglo xv. Ella cita dos ejemplos del Rimado de palacio. El soneto 128 de Petrarca ("Po, ben può tu portartene la scorza...") aprovecha y elabora en forma más sutil esa misma imagen. 
ración tomada de la naturaleza, sino en figura de un caballero rival, la muerte llama a la puerta de don Rodrigo y lo reta a un combate singular

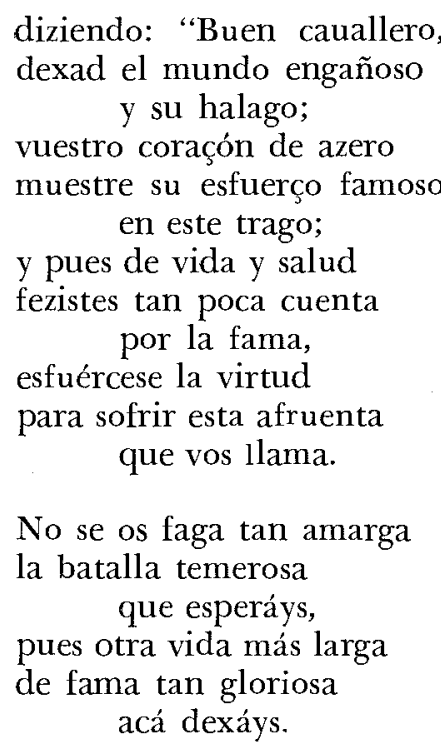

La vida de la fama, que es la vida verdadera de don Rodrigo, debe ahora responder a este último reto, llevar a cabo su hazaña final. Debe rendirse o sufrir la derrota en una "batalla temerosa" con un contrincante que no puede ser vencido. Sin embargo, aquí sólo se alude de pasada al tema de la liza o "paso de la muerte" " . Entonces, ¿por qué aparece? Podría responderse que Jorge Manrique recurre a la tradición de Aimé de Montgésoie y de Olivier de la Marche con objeto de prepararnos poéticamente para la resolución final ("esfuerço famoso") de su padre. Ese "consiento en mi morir" revela a don Rodrigo como "caballero esforzado" en una forma que no hubieran reconocido esos dos poetas (ni Hernando de Acuña o Jerónimo de Urrea, que tradujeron al español a Olivier de la Marche) ${ }^{9}$.

${ }^{8}$ El Chevalier délibéré de Olivier de la Marche es posterior (1483), pero su autor reconoce que ha utilizado el Pas de la mort de Aimé de Montgésoie (que aún vivía en 1478). Sin duda Jorge Manrique no conoció este último poema, pero por él vemos que el lenguaje figurado del combate caballeresco con la muerte era seguramente tradicional. No lo cree así T. Walton, "Aimé de Montgésoie", Annales de Bourgogne, 1930; sin embargo, la imagen se relaciona demasiado con el mundo real y poético del siglo xv para que pueda considerársela como invención de un solo hombre (Walton, desde luego, puede estar en lo justo cuando dice que el Pas de la mort es el primer poema que elabora exhaustivamente la alegoría).

"Véase el completo estudio de C. Clavería, "Le chevalier délibéré" de Olivier de la Marche y sus versiones españolas, Zaragoza, 1950. Clavería no habla del semi-oculto desafío al "esfuerço" de don Rodrigo Manrique. 
Sin embargo, esa respuesta, centrada únicamente en el padre, me parece unilateral. Es incompleta, y por lo tanto, equívoca. Ese hombre agonizante ya ha sido caracterizado detenidamente, y en su respuesta a la muerte, en las estrofas subsiguientes, justificará todo cuanto de él se ha dicho. De los dos interlocutores no es él, por cierto, quien más necesita un refuerzo poético. Me parece, pues, que el lenguaje empleado en el "paso de la muerte" se destina más bien a sugerir indirectamente un retrato de la muerte como caballero armado, es decir, como un hombre de honor, digno de la vida de honor que va a caer bajo su brazo. Salinas estudia esas estrofas bajo el encabezado "La muerte recobra el sentido", y habla de la dignidad con que la muerte se presenta a sí misma. Ese respetuoso llamar a la puerta, ese reto lleno de gravedad corresponden, por su decoro, a la vida que ha sido desafiada. La muerte no debe acercarse a don Rodrigo "tan callando", como un ruin o un cobarde. En otras palabras, al hacer que la muerte hable de sí misma en lenguaje caballeresco, Jorge Manrique logra que la muerte, dejando de ser una figura del espanto y de la incomprensión, se convierta en un ser adecuado a su padre, un caballero igual a don Rodrigo. Esto es lo que Rilke hubiera llamado "semen eignen Tod" ${ }^{10}$. Y he ahí justamente la razón de que no se haya desarrollado más la batalla alegórica. No sólo por ser natural e inevitable, sino también por ser "su muerte", don Rodrigo la acepta "con voluntad plazentera, / clara y pura". La alegoría del "paso" o campo de torneos, tan brevemente sugerida y tan rápidamente abandonada, ha servido para dignificar y ennoblecer al temible interlocutor. La "vida de onor", vida de la cual es responsable cada individuo, ha pintado su propio re-

${ }^{10}$ A Leo Spitzer, "Dos observaciones... a las Coplas de Manrique", NRFH, $4\left(195^{\circ}\right)$, p. 22, nota 3o, no le parece bien que Salinas asocie, a través de la historia, a esos dos poetas de la muerte. "Claro está -dice- que ese mi morir, donde el yo humano acepta el punto de vista de la divinidad..., no tiene nada que ver con las tentativas modernas (Rilke, Malraux, Heidegger) de ver la muerte como acontecimiento humano, integrado en la vida humana, a la cual, por supuesto, da su sentido (el Dasein de Heidegger que es Sein zum Tode), como demuestra bien Sartre..." Se diria que la lectura de Sartre y de Heidegger ha llevado aquí al filólogo por una ruta falsa. No se trata de identificar Weltanschauungen históricas obviamente diferentes, como bien sabía Salinas. Él citó la oración de Rilke en que éste pide a Dios una muerte madurada dentro de la vida, una muerte que evidentemente no viene -ni con disimulo, ni con caballeresca cortesía- desde fuera. El parecido que ve Salinas es de otro tipo. Consiste en la manera como insisten poéticamente los dos, Manrique y Rilke, en que la muerte debe poseer sentido y decoro. Cada uno de ellos es un poeta que se enfrenta al tema de la muerte; cada uno está decidido a luchar contra la muerte por medio de la poesía, o, para decirlo en forma más audaz, a salvar poéticamente a la muerte. Con ese objeto, cada uno de ellos se pone a dignificar y humanizar a la muerte desde dentro de su propia tradición. Para ambos la muerte se convierte, pues, en una persona, no en una personificación macabra y negativa. 
trato de la muerte, la última de aquellas "estorias / que con su braço pintó".

Cuando leemos las Coplas, desde la clara campanada de las estrofas iniciales, pasando por la desnuda alegoría de la mar y los ríos, hasta esa conclusión gravemente personal, sentimos una gradual acumulación de ímpetu, una creciente complejidad de tejido poético. Bajo la superficie de las palabras hay dimensiones cada vez más hondas, abismos de significación cuyo fondo podemos vislumbrar, pero nunca explorar por completo. Este misterioso incremento de carga poética se debe, al menos en parte, al retrato de la muerte. La vida es lo que es, y se encuentra desplegada poéticamente para que todos la vean y la admiren. Pero la muerte, su compañera femenina ${ }^{11}$, es misteriosa y ambigua y se resiste al escrutinio. La nota inicial de portento poético es precisamente ésta, "cómo se viene la muerte / tan callando". A esa intuición de la muerte, mucho más sugestiva que la cruda y descarnada agresora de las Danzas y de los grabados en madera, debe ajustarse la expresión poética. Como acabamos de ver, cuando la muerte habla con su propia voz, lo hace en un lenguaje figurado - "trago", "afruenta", "batalla", "galardón", "partid", "ganaréys"- que sugiere mucho más de lo que dice. Tras la fatal llamada a la puerta, el poeta evita cuidadosamente la presentación directa (el "Io so la muerte" de la Dança) para expresar, en cambio, la promesa de la vida venidera. Y si esto ocurre aquí, al final, ¡cuánto más elusivo es el segundo retrato, el de la muerte que danza con la vida del mundo traicionero! La elusión poética es, en este pasaje, casi completa (aunque no total). Sin embargo, por silenciosa que sea - "sinister and lurking", en palabras de Anna Krause--, su tácita contribución al poema es de enorme importancia.

Desde el punto de vista poético, la especial elusividad del segundo retrato de la muerte trae consigo un cambio de técnica expresiva. La alegoría cede su lugar a la metáfora, a una serie de imágenes visuales que dan a entender intuitivamente cuál es la apariencia de la muerte desde el punto de vista de esta vida. Primero vemos los verdes brotes de las eras que crecen lozanos, ignorantes de la siega, del aplastamiento, de la erradicación que les espera:

Las justas y los torneos,

paramentos, bordaduras

11 La muerte se personifica a menudo como mujer, reflejando el género femenino de la palabra y explotando las macabras posibilidades de los encuentros con ella. (Véanse los ejemplos reunidos por J. Huizinga en su ensayo "Die Figur des Todes bei Dante", Wege der Kulturgeschichte, München, 1930). Sin embargo, no pretendo decir que Jorge Manrique haya querido sugerir esa personificación. Lo que me parece femenino es el papel poético de la muerte: su pasivo abrazarse con la existencia humana, su elusividad misteriosa, su capacidad de seguir las pisadas de la vida y al mismo tiempo contribuir al esplendor de la danza humana. 
y cimeras,

¿fueron sino deuaneos?

¿qué fueron sino verduras

de las eras?

Si nos detenemos un momento en la imagen, sentimos en primer lugar su fuerte sabor bíblico. Parece resultado de la fusión o superposición de dos símiles frecuentes en el Viejo Testamento: 'la carne es como la hierba' ("Serán como grama del campo y hortaliza verde, como hierba de los tejados que antes de sazón se seca", Isaías, 37:27) y 'la muerte es como trillador' ("Por tanto serán como la niebla de la mañana, y como el rocío de la madrugada que se pasa; como el tamo que la tempestad arroja de la era...", - "sicut pulvis turbine raptus ex area", Oseas, 13:3) ${ }^{12}$.

Pero más importante que esa amalgama de comparaciones tradicionales es el carácter directo y visual de la imagen. Así, a Anna Krause la hace pensar en los "campos castellanos, cubiertos de efímero verde". Si prescindimos de su traducción de eras por "campos" (fields), tiene razón. Hay aquí, como en otras estrofas de este segundo encuentro de la vida con la muerte, un empleo poético de la imagen que es mucho más delicado que una mera afirmación emblemática de semejanzas ${ }^{13}$. Pero ¿cómo se logra ese carácter visual, ese efecto de un verde efímero? Yo diría que en la palabra era, con sus dos sentidos, hay otro cruce que contribuye en gran medida al logro poético. Covarrubias nos dice que era es, por un lado, "el pedaço de

${ }^{12}$ He aquí otro pasaje que puede asociarse con las coplas: "Porque no le había quedado gente a Joachaz, sino cincuenta hombres de a caballo y diez carros y diez mil hombres de a pie; pues el rey de Siria los había destruido y los había puesto como polvo para hollar" (II Reyes, 13:7). Hay muchos otros. De hecho, las comparaciones bíblicas en que entra la idea de trillar, desgranar, etc. bien pueden haber dado origen a la tradición medieval de pintar a la muerte montada en un buey o una vaca. H. Rosenfeld, op. cit., p. 15, atribuye esa tradición a "uralte heidnische religiöse Kultvorstellungen", pero quizá esta explicación resulte demasiado misteriosa. Así como la comparación de la carne con la hierba o el heno es el origen remoto del segador macabro, así aquí, por análoga extensión alegórica, la muerte parece haberse convertido en un funesto trillador montado en una vaca.

13 Anna Krause, op. cit., p. 101, habla con gran sensibilidad de la fascinación visual y auditiva de esa imagen: "He widens the field of imagery... evoking the Castilian fields of grain clothed in fleeting green. But a master of sound, he plays upon definite vowels and consonants, verduras, eras..., to heighten the music of his lines". Al Ilegar a estas conclusiones, compara la versión de Manrique con Ios pasajes bíblicos en que se inspira (menciona en concreto el Salmo 103:15) y con otra elaboración análoga de la metáfora bíblica: la de Gómez Manrique en Ias Coplas para Diego Arias. Lo que Anna Krause no ve es que la originalidad de Jorge Manrique, en confrontación con el pasaje del Salmo y el de Gómez Manrique, no depende sólo del color y del sonido, sino también de la forma: la palabra eras sugiere un espacio nítidamente delimitado, y hace pensar en la liza o campo de torneos. 
tierra limpia y bien hollada en la qual se trilla la mies", y, por otro, "el quadro de tierra en que el hortelano siembra las lechugas, rávanos, puerros y otras legumbres". Las eras de la pregunta "¿qué fueron sino verduras / de las eras?" son al mismo tiempo campos de trilla (con su implícito recuerdo del sombrío trillador bíblico) y cuadros de huerto bien regados, cuyo vivido color verde contrasta con el pardo y uniforme del campo español. En otras palabras, hay aquí una ambigüedad: una de las raíces de la imagen es auditiva y se hunde en la tradición, y la otra es visual y pertenece a la experiencia presente; el oído y el ojo, el pasado y el presente se fortalecen uno a otro y confluyen para dar su sentido a la imagen.

Pero lo sugestivo de la imagen no radica sólo en su color. El campo de trilla y el cuadro de hortalizas tienen en común su encerramiento; son "áreas" limitadas y circunscritas, comparables en este sentido al limitado y circunscrito campo de las "justas y torneos" que poéticamente están describiendo. Las matitas de hierba, que con tal ternura y confianza se lanzan hacia arriba, se funden visualmente con las cimeras de los caballeros, con las plumas de los yelmos, las divisas, los jaeces, tan osadamente marciales, tan alegremente firmes y seguros. Hay algo conmovedor, algo que inspira a la vez esperanza y desesperación, en esta repentina mezcla visual de lo rústico y lo guerrero, de fuego y frescor, de clorofila y hemoglobina. La sucesión de plurales _- "justas", "torneos", "paramentos", "bordaduras", "cimeras"- queda encerrada, visual y sentimentalmente, dentro del cerco lineal de las eras y los salientes perfiles de las verduras. No son ya meras palabras en secuencia retórica: se han convertido en miembros visualmente fijados de una imagen, la cual irradia nuevos sentidos a lo largo del poema. Pero ¿¿ónde está aquí la muerte? Está sólo sobreentendida: es el trillador o el segador, o quizá el pesado buey que tan pronto cortará o aplastará ciegamente esta vida. Jorge Manrique evita las comparaciones mecánicas y prefiere ahora sugerir la muerte como posibilidad no realizada de una imagen. La muerte, sombrío trillador o segador, es la causa no expresada de una destrucción no expresada, la tácita condición de nuestra nueva y agudizada consciencia de lo transitorio. Podemos percibirla, pero no la vemos. El doble logro de Manrique consistió en recapturar la poesía de las metáforas bíblicas originales y en aludir a la vez, tan eficazmente, a sus derivaciones emblemáticas de la tardía Edad Media. La punta mortal ha quedado como afilada y enderezada.

Igual abandono de la alegoría puede verse en las dos imágenes siguientes, la del rocío de los prados y la del agua en la fragua:

Las dádiuas desmedidas,

los edificios reales

llenos de oro,

las vaxillas tan febridas, 
los enrriques y reales

del tesoro,

los jaezes, los cauallos

de su gente, y atauíos

tan sobrados,

¿dónde iremos a buscallos?

¿qué fueron sino rocíos

de los prados?

Pues su hermano el ynocente,

que en su vida sucessor

se llamó,

¡qué corte tan excelente

tuuo, y quánto grand señor le siguió!

Mas como fuesse mortal, metiólo la Muerte luego en su fragua.

¡O juyzio diuinal!

Quando más ardía el fuego, echaste agua $^{14}$.

La primera de estas estrofas está llena de brillo y resplandores. El bruñido lustre del oro, de las vajillas, de las monedas apiladas del tesoro real, se contagia poéticamente a los arneses, las monturas y los arreos de los cortesanos de don Enrique. La sensación visual, una vez fijada, ilumina las demás series de objetos, y nos vemos metidos en un mundo resplandeciente cuya superficie y apariencia se han transmutado. Pero, a diferencia de lo que ocurre con el mundo del rey Midas, esta metamorfosis está ligada al tiempo. No llega hasta la sustancia. De ahí la última imagen visual, que, compendiando todas las demás, expresa a la vez lo maravilloso y lo perecedero del ambiente regio: “¿que fueron sino rocíos / de los prados?” "15 El impla-

14 Sobre la última imagen dice Anna Krause, op. cit., p. 174: "The same curious image is used to bring out the contrast between courtly splendor and the grim shadow of death in the... Question de amor (1512): "En tanta manera que, movida la fortuna de enemigable embidia, començó a poner en medio deste fuego una fuente de agua tan cruel y fría, que la mayor parte, como agora se diría, casi consumió»..."; otra pareja análoga se encuentra en varios pasajes de Quevedo (por ejemplo, "Amor constante más allá de la muerte", o "Exageraciones de su fuego"). En estos casos han desaparecido el funesto herrero y su fragua, pero la muerte sigue oponiéndose al amor como el agua al fuego.

${ }_{15}$ Anna Krause cita varios ejemplos (Pero López de Ayala, Martínez de Medina, Gómez Manrique) del empleo de rocio como imagen de fugacidad; en ninguno de ellos se ha sacado todo el partido poético de la palabra, es decir, no se alude a sus connotaciones visuales de brillo y hermosura. Para esos poetas, el rocio es un mero signo convencional ("Todas estas rriquezas son niebla y rroçío", etc.). Véase un empleo bíblico análogo en el ejemplo citado supra. 
cable y corrosivo sol de la muerte no se menciona explícitamente, ni hace falta mencionarlo. Una vez más, el poeta deja que se acerque "tan callando" la enorme agresión que viene de fuera. En cuanto a la fragua de la segunda estrofa, la comparación directa de la muerte con un herrero y de la juventud con el fuego es mucho menos importante que el repentino, inexplicable apagarse de las llamas. Esta imagen, tanto más eficaz cuanto que va contrapuesta a la de la evaporación del rocío, contiene elementos de una alegoría inconclusa, imperfecta ${ }^{16}$. Pero la llamarada y su absurda extinción (" $\mathrm{O} O$ juyzio diuinal!") se comprenden mejor como un correlato objetivo, no sólo de la extinguida mocedad caballeresca del príncipe don Alfonso, sino también de las aspiraciones políticas de Castilla ${ }^{17}$.

Esta calculada cadena de metáforas básicas, que comienza con la hierba de la tierra y continúa con el agua y el fuego, termina con la luz:

$$
\begin{aligned}
& \text { Pues los otros dos hermanos, } \\
& \text { maestres tan prosperados } \\
& \text { como reyes, } \\
& \text { que a los grandes y medianos } \\
& \text { truxieron tan sojuzgados } \\
& \text { a sus leyes; } \\
& \text { aquella prosperidad } \\
& \text { que tan alta fue sobida } \\
& \quad \text { y ensalçada, } \\
& \text { ¿qué fue sino claridad } \\
& \text { que estando más encendida } \\
& \text { fue amatada? }
\end{aligned}
$$

Aquí, curiosamente, el elemento visual no es primario. El conjunto está construido sobre una ambigüedad semántica: el doble sentido de 'nobleza' y 'luz' que tiene la palabra claridad. Esto queda patente en el verbo final, amatar 'apagar el fuego', donde hay asimismo un juego semántico, pues a través de él se trasluce matar. Una vez más, la muerte sólo está presente por alusión. El empleo de un verbo que designa una acción cotidiana y doméstica hace pensar que el agente - símbolo de la muerte - sea también un personaje de la vida cotidiana y doméstica, quizá un criado que ejecuta su última

${ }^{10}$ Narciso Campillo, el editor de Bécquer, hizo notar la imperfección de esa imagen en cuanto intento de alegoría (Florilegio español, Madrid, 1885). Cito a Campillo a través de E. Tomé, Jorge Manrique, Montevideo, 193o, p. 87).

${ }_{17}$ Tanto en el aspecto personal como en el histórico-político, esta muerte resulta ser antítesis de la de don Rodrigo. Es una muerte prematura, no sólo carente de sentido, sino, más aún, contraria a todo sentido. De ahí la "leise Bitterkeit", el "flüchtige Zweifel an der göttlichen Gerechtigkeit" que RoseMARIE BURKhaRT percibe en el verso ";O juyzio diuinal!"; Jorge Manrique no habría aceptado seguramente tal interpretación, pero, al menos, es ésta una muerte en la que él juzga difícil "consentir". 
tarea del día. A medida que va apagando una a una las candelas (los nobles), deja la corte a oscuras: la oscuridad de la deshonra. Del juego verbal hemos sido llevados a la imagen, de la claridad al concepto implícito de una final oscuridad sin sentido. Vemos -o, mejor, no vemos- la oscuridad.

¿Qué nos dicen sobre la muerte esas cuatro imágenes? ¿Qué infiere Manrique de esa muerte a que se enfrenta la vida terrena de cada hombre, a que se enfrenta cada uno de nosotros? Desde hace mucho estamos acostumbrados a interpretar esta parte del poema como una evocación nostálgica del pasado cortesano del propio Manrique. "Otro personaje hay que yo vislumbro - exclama Salinas (p. 375 )-, el más conmovedor de todos, allí en medio de ese torbellino de encantos cortesanos. El mismo poeta, Jorge Manrique". Indudablemente tiene razón. Pero al mismo tiempo, y a pesar de la admiración del poeta por los esplendores de esa vida - pompas festivas, riqueza, juventud, nobleza y todo lo demás-, debemos recordar que, como la hermosura de los fuegos de artificio, su atractivo se intensifica por su misma fugacidad. Son los que Calderón calificaría de "llamas de la muerte". Entreverados con la muerte, dependen de ella como una fotografía de su negativo. Pero ¿cómo es esa muerte escondida? ¿En qué forma difiere la segunda imagen de la muerte de la impersonal mortalidad del comienzo y de la inmortal personalidad de la última parte? Ante todo, es repentina e inesperada. Es una muerte que "amata" patéticamente la vida, sin necesidad ni motivo. No es genéricamente necesaria, como la primera, ni tampoco la culminación, largo tiempo elaborada, de una vida llena de sentido, como lo será la última. Es, por el contrario, esa muerte de la cual se ha dicho que nos llega "desde fuera", cósmico "mecanismo... que sobreviene a la vida"1s. La agresión, increíble, llega sin anunciarse; no hay defensa contra ella; apenas queda tiempo para un grito.

Pero la súbita y dolorosa interrupción no agota el retrato implícito de la muerte que en esas metáforas se pinta. Las metáforas sugieren también una terrible desproporción de tamaño y de sentido entre víctima y verdugo. Lo que el sol es a la gota de rocío, el segador a la hierbecilla, el criado a la candela, eso es la muerte al individuo. Ante nosotros - parece decirnos Manrique- tenemos un universo extraño, horripilantemente enorme y gobernado por finalidades que quedan para siempre fuera de nuestro alcance. La nostalgia y ternura de esta parte de las Coplas existe en función del terror: el terror que sentimos al darnos cuenta plenamente de la enormidad del contrincante. Sólo una vida de heroísmo, de santidad auténticamente vivida (la "vida de onor" que, como veremos, no es al final

${ }^{18}$ J. Ferrater Mora, El sentido de la muerte, Buenos Aires, 1947, p. 266. 
del poema lo mismo que la "vida de la fama"), puede poner a la muerte a la altura del hombre. De ahí que, cuando el poeta interpela a la muerte al final de esta sección - - "di, Muerte, ¿dó los escondes / y traspones?"-, ella no responda ni se muestre; ha perdido los arreos sepulcrales, la voz hueca y el fúnebre espanto que desplegaba en las Danzas y en el Dit des trois morts. Lo macabro es, en resumidas cuentas, un aspecto de lo humano; pero este invisible retrato es a-humano: está más allá de nuestros conocimientos. Como ha dicho Salinas, Jorge Manrique descarta por superficial "la macabra, la truculenta y empavorecedora versión de nuestra mortalidad" (p. 211$)^{19}$. El verdadero horror de esta muerte se debe a que no tenemos contacto con ella. Sólo es posible sugerirla con metáforas, vislumbrarla como tácita consecuencia de una comparación. Al evitar la descripción horripilante, Manrique logra expresar mejor que ningún otro poeta español aquello que Maritain llama "la angustia existencial de fines del siglo xv" 20 .

$\mathrm{El}$ invisible y silencioso retrato que acabamos de reconstruir ostenta un detalle explícito que vale la pena comentar, por ser único. Se nos dice concretamente que el arma fatal de la muerte es una flecha:

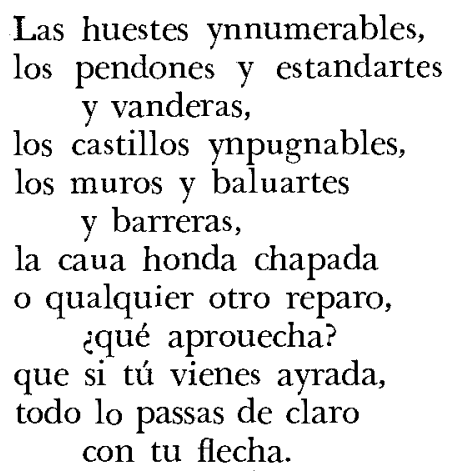

Salinas ha percibido la desproporción poética de este pasaje: "Impresionante efecto sentir que tantas masas de piedra, tantas láminas de hierro no valen contra una, contra una sola saeta, y que el gran peso, el enorme poderío de la muerte, se condense y afine todo en esa forma leve de una varilla con la punta acerada" (p. 179). En otras palabras, el carácter increíble de la muerte, sugerido por las metá-

19 ANNA Krause interpreta esto como "Renaissance joy in bodily prowess and beauty", ofreciendo así una explicación histórica absoluta para algo que es, en último término, una intuición poética, según ha mostrado Salinas. Esa idea la lleva a afirmar que no hay "ningún eco" de lo macabro, cuando, de hecho, Manrique no vacila en explotar por lo menos un eco o reminiscencia de lo macabro - la flecha- al ensalzar la vida de este mundo.

${ }^{20}$ Jacques Maritain, Creative intuition in art and poetry, New York, 1957 , p. 21. 
foras precedentes, queda resumido en un rasgo final preñado de asombro, del mismo asombro que se expresa en ese diminutivo $\mathrm{cu}$ chillito de García Lorca, o en esa muerte de Ricardo II que "comes at last and with a little pin / bores through his castle wall, and farewell king".

Hay que recordar, sin embargo, que esa flecha mortal no es invención poética de Jorge Manrique. De hecho, durante el siglo xv la muerte se representaba, más que como segador, como un horrendo cazador o arquero. El arco y la flecha, o el venablo arrojadizo, que tiene antecedentes en el $\dot{\epsilon} \kappa a \tau \dot{\beta} \beta o \lambda o s$ de Homero y en algunas expresiones de Job - "las saetas del Todopoderoso están en mi" (6:4), "cercáronme sus flecheros" (16:13)-, se convirtieron en lugar común de las imágenes medievales de la muerte ${ }^{21}$. Ésta dice al comienzo de la Dança española:

Io so la muerte çierta a todas criaturas...

Pues non ay tan fuerte nin rezio gigante

que deste mi arco se puede anparar,

conuiene que mueras quando lo tirar[e]

con esta mi frecha cruel traspasante.

Así, pues, es poco probable que la patética sorpresa causada por esa arma ligerísima constituya una explicación suficiente. A semejanza de "las verduras de las eras", "tu flecha" trae consigo el recuerdo de la iconografía coetánea. Manrique utiliza como refuerzo poético "la empavorecedora versión de nuestra mortalidad", no directamente, sino por asociación con su arma tradicional, la flecha. Las connotaciones purificadas de horror y miedo (purgadas de la escoria de las descripciones torpes y de mal gusto) contribuyen a prestar a este mundo transitorio un aspecto más hermoso y deseable. Salinas está en lo justo cuando muestra cómo Manrique rechaza la intimidación externa. Pero no significa necesariamente que el poeta haya esquivado del todo las actitudes y reacciones de sus contemporáneos, que bien podían servirle de material poético. "Todo lo passas de claro / con tu flecha" es ejemplo ilustrador de esas alusiones sutiles y calculadas con que Manrique pintó su segundo retrato de la muerte.

Observemos, por último, la concordancia poética que existe entre esta arma y la base marcial del conjunto. Como observó Quintana

${ }^{21}$ Véanse las ilustraciones reproducidas por F. PARRes WEBer, H. RosenFeld y E. MÂle; C. Clavería, op. cit., ofrece una serie de ejemplos gráficos y literarios de índole diversa, y cita esta acotación escénica de la Farsa de la muerte de Diego Sánchez de Badajoz: "la muerte se puede hacer con una máscara... con su aljaba a las espaldas llena de saetas y un arco en la mano con su harpón" (p. 104). Más cercano a las Coplas está el grabado en madera que aparece en la primera página de la Glosa de Diego de Barahona (véase la ed. facs. de A. M. Huntington, New York, 1902), que representa a la muerte armada de una enorme flecha. 
en son de crítica ${ }^{22}$, las Coplas, pese a su lirismo de composición y expresión poética, carecen de verdadero ambiente lírico. En un sentido profundo, son épicas por su valoración de la vida y por su retrato de la muerte. Ya hemos oído cómo la muerte se dirige a don Rodrigo empleando el lenguaje en que un guerrero habla a otro, y ahora, como preparando ese encuentro final, vemos a la "ayrada" muerte guerreando con las nobles huestes de Castilla. La táctica es sumamente eficaz. Sin exponerse ni manifestarse en absoluto, la muerte dispara desde lejos, derribando a un caballero tras otro. ¿No hay en esa elección de su armas una idea implícita de cobardía $\mathrm{o}$, al menos, de falta de nobleza? Recordemos no sólo a Paris y Aquiles, sino también al morico de "Álora la bien cercada", que en 1434 mata al magnífico don Diego de Ribera con un solo tiro de ballesta, disparado desde su escondite "entre almena y almena". Otra mano, igualmente innoble, arroja la saeta que da muerte al "esforçado gentil cavallero" Garcilaso de la Vega, llorado en desgarbados versos por Gómez Manrique ${ }^{23}$. En las guerras de la Edad Media (según nos informa Hansard en su curioso Book of Archery) eran frecuentes tales $\operatorname{casos}^{24}$. Una pieza que faltaba en la armadura, una visera alzada, una rotura inesperada, y el más honrado y valiente caballero caía por tierra con estrépito. Por eso el Tamorlán de Marlowe habla del funesto arquero como de un "esclavo" que, descolorido y tembloroso, sólo se atreve a disparar desde lejos ${ }^{25}$. Jorge Manrique no es, desde luego, tan explícito en su desaprobación; pero salta a la vista el contraste entre ese arquero mudo y escondido y el grave y noble retador que respetuosamente llega a tocar a la puerta de don Rodrigo “en la su villa de Ocaña”. Añade así otro matiz negativo a ese retrato de la muerte como cosa inhumana, in-

${ }^{22}$ Manuel José Quintana, Tesoro del Parnaso, nota a las Coplas.

${ }^{23}$ "Defunzión del noble cauallero Garçilasso de la Vega" (Cancionero de Gómez Manrique, ed. A. Paz y Mélia, Madrid, 1885, t. 1, p. 104): "Llorauan, plañían parientes y ermanos / por ser asi muerto por un vallestero / aquel esforçado, gentil cauallero / que otro mejor no fue por sus manos". En cuanto al traicionero morico de Álora, obsérvese el parecido que guarda, en cuanto al lugar en que se encuentra y a su acción, con la figura de la muerte que aparece en la Batalla de la muerte $(1558)$ de Pedro de Sayago: "Sale con la flecha armada / la Muerte detrás del muro" (cit. por Cravería, p. 101). En este y otros ejemplos, la fatal saeta no sólo atraviesa los muros, sino que es disparada al amparo mismo de los muros.

${ }_{24}$ G. A. Hansard, The Book of Archery, London, 1841, pp. 56-59. En el prefacio (p. x), Hansard cita a Sir John Smyth, según el cual "French captains and gentleman attribute all former victories of the English... more to the effect of our archers than to any extraordinary valiance of our nation".

25 Tamburlaine the Great, Part. II, Act. V, scene 3: "See, where my slave, the ugly monster, Death, / shaking and quivering, pale and wan for fear, / stands aiming at me with his murderous dart, / who flies away at every glance I give, / and when I look away, comes stealing on". 
calculable, ajena. Por un momento al menos, la muerte parece presentarse como el verdadero "traydor", mientras la vida "en este mundo" se viste de esa belleza nostálgica y compungida que tantos lectores han percibido en la parte central del poema. La representación negativa de la muerte - tan cuidadosa y sutilmente indirectaes condición previa de la salvación poética que Manrique otorga a la vida inmanente en esa porción central de las Coplas. De ahí que Américo Castro pudiera dar a su espléndido ensayo sobre el poema el sencillísimo título de "Muerte y belleza".

He tratado hasta ahora de examinar críticamente algunas de las técnicas poéticas - sugerencias, connotaciones, ideas implícitas, ambigüedades - con las cuales Jorge Manrique logra dar tan profundas resonancias a la superficie del pensamiento y la palabra tradicionales. Contemplemos por un momento a la luz de la historia los resultados obtenidos. Desde Huizinga para acá, la polaridad axiológica de todo el "otoño" de la Edad Media es bien conocida. José Luis Romero la explica en esta forma:

En el ambiente de crisis que caracteriza la baja Edad Media, la concepción del hombre acentuó su bipolaridad al romperse el equilibrio establecido sobre la preeminencia de lo espiritual, de lo referido al trasmundo, de lo que pertenecía a la ciudad celeste. Ese equilibrio no se constituyó sobre nuevas bases, sino que, simplemente, los elementos encontrados permanecieron en presencia, oponiéndose o contemplándose en síntesis transitorias e inestables... Quienes componían los versos de la Danza macabra -en las numerosas versiones que aparecieron por entonces- estaban lejos de despreciar el mundo, y si despreciaban la vida era tan sólo por la desilusión que sentían por su brevedad y su incertidumbre. . ${ }^{26}$

Así, pues, la obsesiva preocupación que los hombres del Cuatrocientos sentían por la muerte es el correlato de un apasionado y violento amor a la vida. Más que un "lugar común", ese crudo y estéril contraste era, como diría Ortega, "el tema de aquel tiempo". Tema que Jorge Manrique tenía que conocer, a pesar de que sabía perfectamente, como lo supo Huizinga, que semejante visión de la vida y la muerte no representa la emoción del consuelo y "no conoce ni el aspecto elegiaco ni la ternura"27.

Ya hemos visto la solución. Jorge Manrique no trata de anular

26 J. L. Romero, La Edad Media, México, 1949, pp. 197-198. Añade este autor que la peculiaridad temática de las Coplas se debe a una diferencia en la actitud social, "y ese sentimiento era mucho más popular y estaba mucho más difundido que la actitud religiosa y moral -señorial en el fondo- que caracterizaba a Jorge Manrique". Esto tiene indudable interés para nuestro problema, aunque las actitudes sociales no escriben poemas por sí mismas. En última instancia, es Jorge Manrique quien debe expresar y definir su nobleza superando el dualismo muerte-vida.

27 Huizinga, El otoño de la Edad Media, trad. cit., p. 219. 
la bipolaridad de buenas a primeras, ni tampoco propone una nueva síntesis histórica. Prefiere asimilar poéticamente el dualismo, conferirle refinamiento elegiaco y ternura por medio de su dominio de la alusión y de la metáfora. Por lo menos en esta parte central de las Coplas, Manrique pinta a la muerte de tal manera, que transforma y salva el otro polo, la vida. La una es todopoderosa y extraña, ajena e inasible, mientras que la otra está nostálgicamente presente y es hermosa en su humanidad, su debilidad, su fugacidad. Es la respuesta a Huizinga. La poesía ha conquistado a la historia.

Pero ¿qué decir del final del poema? Ese tercer encuentro de la vida y la muerte ¿no representa una solución del dualismo, una síntesis de sus términos antitéticos? Yo diría que sí. Pero para ver en qué forma ocurre esto, miremos nuevamente la estructura del poema en su conjunto. El encuentro inicial de vida y muerte es genérico e impersonal. Tiene la anonimía de una fábula o de una alegoría medieval. La vida va a dar a la salvación por la muerte como los ríos van a dar a la mar. La peregrinación cristiana ("Este mundo es el camino / para el otro") y el transcurso temporal de la fatalidad biológica son una sola cosa para todos los creyentes. El hombre vive bajo un dosel de orden, a la vez cósmico y cristiano, y debe ajustar sus acciones a esa unidad: "Este mundo bueno fue / si bien vsássemos dél..." Pero la vida, como bien sabía ese hombre del siglo xv, no sólo se vive como una peregrinación, como un avanzar desde abajo hacia arriba. No sólo vivimos bajo el cielo, sino también, y apasionadamente, dentro de la naturaleza, de la historia y la sociedad, dentro de las complejas circunstancias de nuestras vidas. Desde este punto de vista, la muerte es una interrupción venida de fuera, el desorden traído por un intruso cósmico. En la segunda parte Manrique acepta, pues, el dualismo de su tiempo e introduce la historia personal y nacional - modas, batallas, ambiciones, pasiones, bienes de fortuna - dentro del esquema previo de unidad cósmica. Ya hemos visto que se muestra más nostálgico que violento en su culto de la vida y más alusivo que macabro en el aterrador retrato de la muerte. Pero el dualismo, la bipolaridad de vida y muerte, en pugna patéticamente desigual, subsiste aún.

En la tercera parte, Jorge Manrique quiere lograr la reconciliación de "la vida de onor". Esta última forma de vida no es una peregrinación alegórica y amorfa ni tampoco un comercio personal con el mundo. Sobre todo, no debe equipararse sin más con el tópico de la "vida de la fama"28. En la parte central se nos dice categóri-

28 Asi lo ha puesto de relieve María Rosa Lida de Malkiel, La idea de la fama..., México, $195^{2}$, p. 292, quien además señala convincentemente y comenta con gran sensibilidad las resonancias épicas y medievales que hay en el poema. 
camente que la fama, por sí misma, es tan perecedera como todo lo de este mundo:

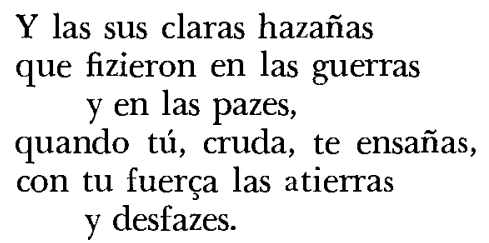

Pero si Jorge Manrique no es un adorador de la fama en cuanto tal, sí tiene, en cambio, un enorme respeto al honor. Su padre no trató de obtener gloria personal ni de conquistar renombre, sino que renunció a sí mismo tanto en la acción como en la fe: "Después de puesta la vida / tantas vezes por su ley / al tablero..." ; fruto de esta renovación del lugar común es una doble terminología:

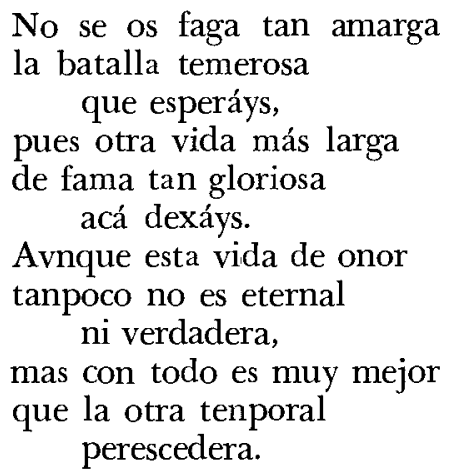

La fama, parece decirnos Manrique, sólo tiene sentido en cuanto aspecto del honor, del verdadero honor, el que se gana luchando en la frontera, "con trabajos y aflicciones / contra moros". Este voluntario retorno a lo épico - primero, la conquista de la fama individual; ahora, el honor alcanzado en la lucha al servicio de Dios y del Rey- es en cierto sentido un programa para la historia futura. Expresa la voluntad que tiene España de no dejar declinar la Edad Media. No es un azar que los contemporáneos llamaran a don Rodrigo Manrique "el segundo Cid" ${ }^{29}$. Para un héroe de su talla, el honor no puede ser un fin en sí mismo, sino un camino hacia la salvación de la "vida tercera": "esperad el galardón / que en este mundo ganastes / por las manos". O, como dice Américo Castro (quien ve aquí una nueva versión de la salvación musulmana a través de la guerra santa): "La vida terrena de don Rodrigo Manrique se

${ }^{29}$ Véanse no sólo los Claros varones, sino también la citada "Defunzión de... Garçilasso de la Vega", donde el hermano de Rodrigo, Gómez Manrique, observa (ed. cit., p. 106): "le armó cauallero en una gran lyd / Rodrigo Manrique, el segundo çid". 
trasciende en una doble salvación: la infinita del vivir celestial, la máxima del sobrevivir terreno" 30 .

Aqui, sin embargo, nos hemos ocupado menos de las actitudes frente al yo o frente a la historia que del nuevo carácter dado a la muerte por medio de esa re-definición y re-dedicación de la vida de la fama. Como resultado de esto, la muerte llega a ser el alter ego de don Rodrigo. No es ya sólo, como dice Anna Krause, un "benévolo consejero" o un "ángel guardián", sino un guerrero ennoblecido y humanizado, que con toda cortesía hace su reto definitivo. Tal es la muerte de don Rodrigo, la muerte que se ha ganado y se ha creado con su propia vida, la muerte que lo llevará al otro mundo y a la otra vida prometida al comienzo. Es la primera vez que el caballero no lucha, ni necesita luchar. Consiente en su morir y se confía en la clemencia de Cristo ("Tú que por nuestra maldad..."). Tras lo cual, paradójicamente, la muerte queda vencida y, de hecho, desaparece del poema ${ }^{31}$. La salvación genérica ofrecida por "aquel fijo de Dios" se ha logrado de manera personal, en una plegaria que supone diálogo entre una primera persona y una segunda persona.

Así se funden al final las tres vidas en una sola. La auténtica "vida de onor" no es una entidad conceptual independiente, sino - como la auténtica santidad- una fusión de la existencia personal con la existencia genérica, un sendero que conduce desde dentro hacia más allá, una conquista del cielo por el $y o^{32}$. El dualismo de vida y muerte "en el mundo" ha quedado trascendido por un honroso abrazo. Ambas se hacen una sola en ese último "morir viviendo" - para invertir el orden de Santa Teresa y don Quijote- que se logra por el honor; y al hacerse una sola, conducen a la frontera del misterio, la frontera de la vida sin muerte, más allá de la cual el hijo no puede seguir al padre, ni el poeta seguir el tema. Como todos los buenos poemas, éste se termina a sí mismo. Como todos los grandes poemas, redefine sus palabras $\operatorname{claves}^{33} \mathrm{y}$, en la última

${ }^{30}$ A. Castro, "Cristianismo, Islam, poesia en Jorge Manrique", en Origen, ser y existir de los españoles, Madrid, 1959, p. 77.

${ }^{31}$ En sus últimas palabras de reto, la muerte había hecho una promesa: "partid con buena esperança, / que estotra vida tercera / ganaréys". El adjetivo tercera se refiere evidentemente a la doctrina de las tres vidas, aunque la vida eterna, según hemos visto, es la primera que se presenta en las Coplas. Primera desde el punto de vista del poema y única importante desde el punto de vista doctrinal, esa vida es tercera sólo para el individuo que logra llegar a ella, tras un escalonamiento adecuado de acciones, al final de su vida.

${ }^{32}$ EI "paso de la muerte" es, para Jorge Manrique, el único combate en que una honrosa rendición equivale a la victoria. Por eso no desarrolla la alegoria, sino sólo la sugiere.

${ }_{33}$ "Avnque esta vida de onor / tanpoco no es eternal / ni verdadera, / mas con todo es muy mejor / que la otra tenporal / perescedera". Tal es el texto de la estrofa en que Manrique intenta por vez primera esa redefinición fundamental. Aquí el poeta no parece aún plenamente consciente de lo que ha 
redefinición, propone un sentido más allá del sentido, un infinito que no puede conocerse y hacia el cual proyecta su luz para siempre.

En esta luz del poema,

todo,

desde el más nocturno beso

al cenital esplendor,

todo está mucho más claro.

Harvard University.

Stephen Gilman

logrado, aunque si se ve que se ha iniciado un proceso de cambio de significación. Por sí o en sí misma, "la vida de onor" no es sino "la vida de la fama" y está, en consecuencia, sujeta a una segunda muerte de olvido, "la otra muerte" que Salinas cita de una traducción de Boecio (p. 212). Pero vista heroicamente y como dedicación de la propia vida, puede conducir a la salvación (véase el análisis que de esta clase de heroísmo hace Max Scheler, "Zum Helden", Schriften aus dem Nachlass, t. 1, pp. 339-344). De ahí que sea "muy mejor". La forma especificamente española de la "vida de onor" es, como ha mostrado Castro, la dedicación a la guerra santa: "trabajos y aflicciones contra moros". 